\title{
Global earthquake and volcanic eruption risk management activities, volcanic hazard assess- ment support system and Asia-Pacific region hazard mapping project in G-EVER
}

Geological Survey of Japan, AIST, Site7, 1-1-1, Higashi, Tsukuba 305-8567, Japan. E-mail: s-takarada@aist.go.jp

The Asia-Pacific Region Global Earthquake and Volcanic Eruption Risk Management (G-EVER) Consortium among the Asia-Pacific geohazard research institutes was established in 2012 with the main objective of reducing the risk caused by earthquakes, tsunamis and volcanic eruptions worldwide. The first G-EVER workshop was held in Tsukuba, Japan in February 2012. The G-EVERI accord was approved by the workshop participants which made 10 recommendations that focused on the enhancement of collaboration, sharing of resources and making information about the risks of earthquakes and volcanic eruptions freely available and understandable. The G-EVER Promotion Team in Geological Survey of Japan was organized in Nov. 2012 to coordinate the G-EVER related activities. The G-EVER $H u b$ website was setup to promote the exchange of information and knowledge about volcanic and seismic hazards among the Asia-Pacific countries. Establishing or endorsing data interchange and analytical methods standards for geohazard institutes of the world are important to promote data sharing and comparative analyses. Several G-EVER Working Groups and projects were proposed such as the Next-generation volcanic hazard assessment $W G$ and the Asia-Pacific region earthquake and volcanic hazard mapping project. The volcanic assessment support system is developed based on eruption history, volcanic eruption database and numerical simulations. The G-EVER hazard assessment support system is implemented with user-friendly interface, making the risk assessment system easy to use and accessible online. The Asia-Pacific region earthquake and volcanic hazard mapping project aims to make a sophisticated online hazard information system that provides past and recent earthquake and volcanic hazards information, risk assessment tools for earthquake and volcanic eruption hazards and links to global earthquake and volcanic eruption databases. The hazard mapping project plans to create the system with the cooperation of Asia-Pacific countries.

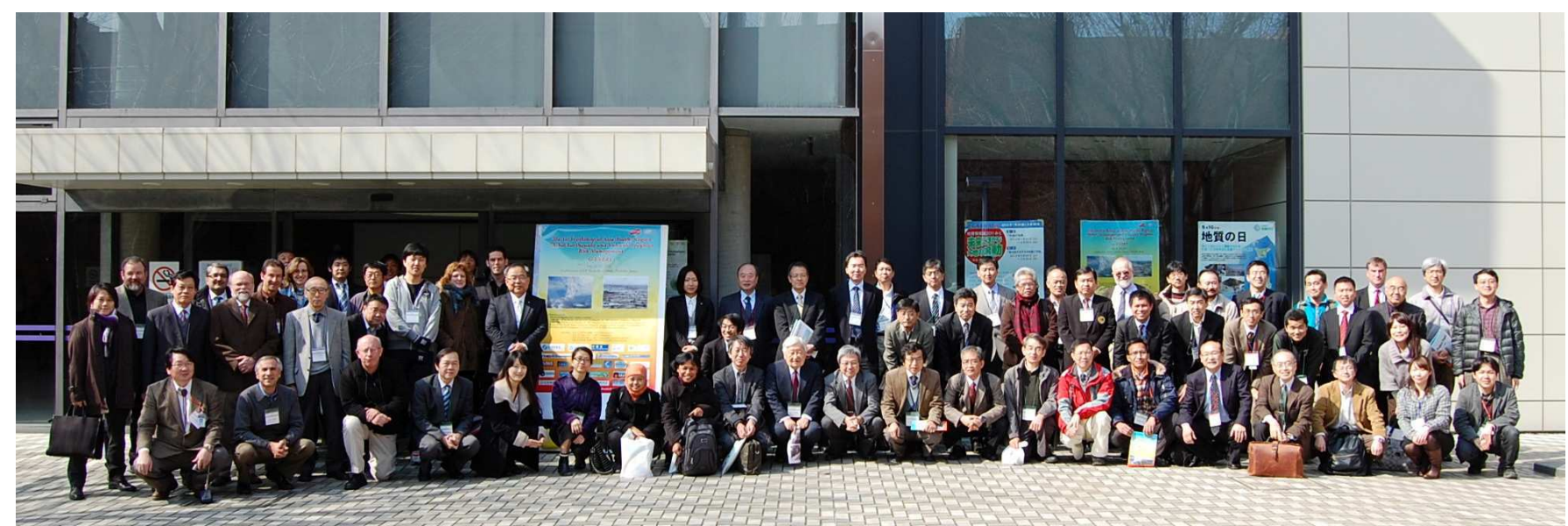

Figure 1. The first workshop of Asia-Pacific Region Global Earthquake and Volcanic Eruption Risk Management (G-EVER1) at AIST, Tsukuba, Japan, February 22-24, 2012. 


\section{Introduction}

The Asia-Pacific Region Global Earthquake and Volcanic Eruption Risk Management (G-EVER) Consortium among the geohazard research institutes in the Asia-Pacific region was established in 2012. G-EVER aims to formulate strategies to reduce the risks caused by earthquakes, tsunamis and volcanic eruptions worldwide (Takarada, 2013a).

\section{G-EVER activities}

The First Workshop on Asia-Pacific Region Global Earthquake and Volcanic Eruption Risk Management (G-EVER1) was held in Tsukuba, Japan from February 22 to 24, 2012 to discuss measures in order to reduce the risks of disasters caused by natural geohazard events like earthquakes, tsunamis, and volcanoes worldwide (Fig. 1).
There were 152 participants from 12 nations and regions and, 56 from national and international institutes. Participants were deeply saddened by recent disasters that occurred in Sumatra, Christchurch and Tohoku, but were also encouraged by successful cases of mitigation and progress on a various of local and global risk reduction efforts. We believe that increased international collaboration between geohazard institutes and organizations in the Asia-Pacific can advance the science of natural hazards thereby, contributing to the reduction of disaster risks from earthquakes, tsunamis, and volcanic eruptions. The participants approved the G-EVER1 accord during the workshop and the following recommendations were made:

1. Establish a consortium of Asia-Pacific geohazard research institutes, with the goal of enhancing collaboration, sharing resources, and making information about risk from earthquakes

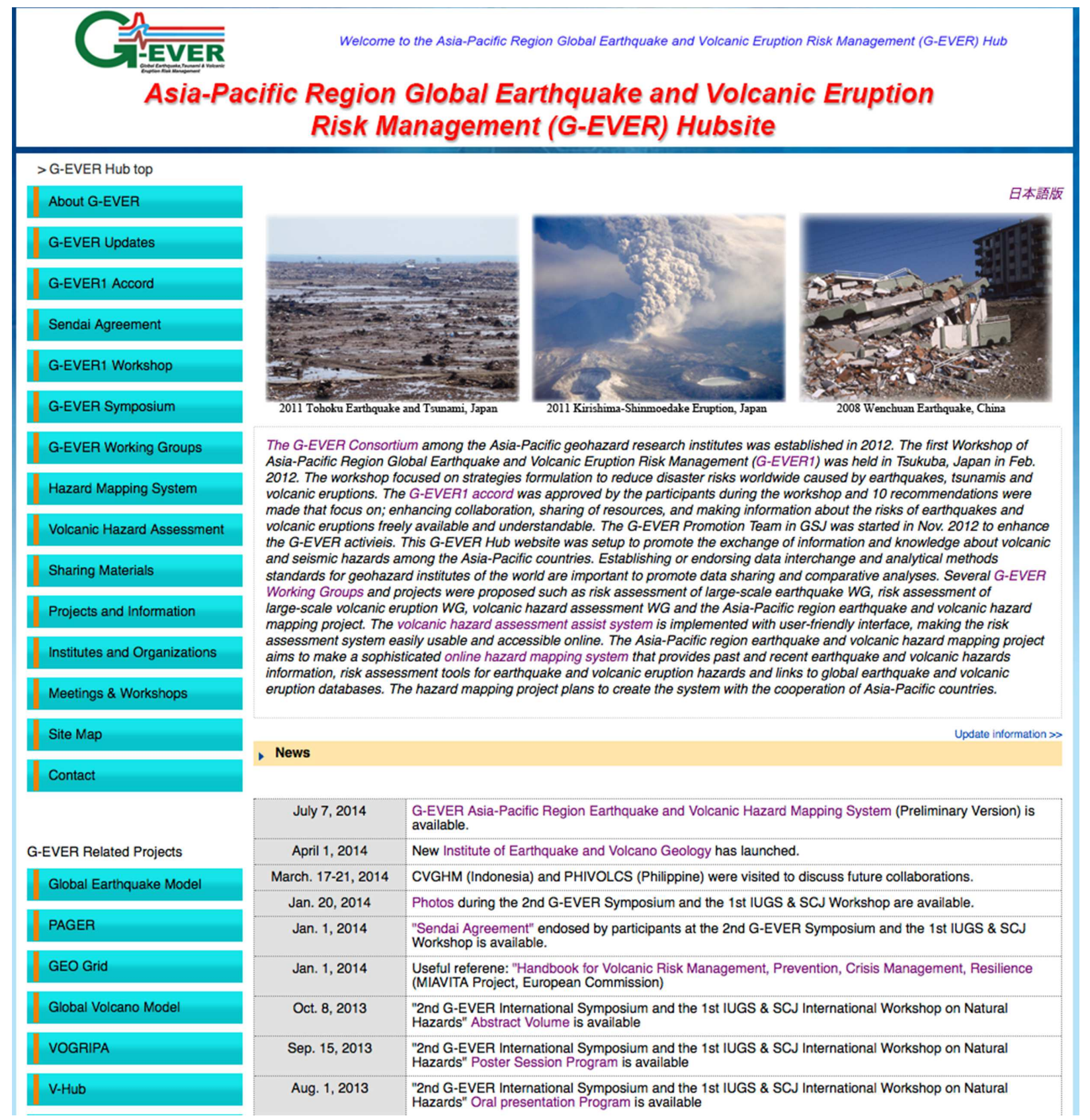

Figure 2. G-EVER Hub site (http://g-ever.org). All G-EVER related information is available on this website. 
and volcanic eruptions freely available and understandable.

2. Promote the use of hazard information in decision-making by citizens, governments, and businesses, so our science supports mitigation actions.

3. Develop a website hub for the consortium in English and major Asian languages, which would link to websites of allied global efforts, such as VHub, GEM Nexus, and the International Seismological Centre (ISC).

4. Establish or endorse data interchange standards and standardized analytical methods for geohazard institutes of the world to promote data sharing and comparative analyses.

5. Actively participate in related global risk reduction efforts, such as the Integrated Research on Disaster Risk (IRDR) Program, Global Earthquake Model (GEM), Global Volcanic Model (GVM) and their component databases like World Organization of Volcano Observatories Database (WOVOdat) and GEM Faulted Earth.

6. Promote "the borderless world of science" with trans-border hazard maps built using common data sets, more uniform and advanced methods and software than has been possible in the past.

7. Promote exchange visits among researchers of the consortium, and encourage opportunities for graduate study in geohazards.

8. Encourage the formation of working groups for broad, multidisciplinary, and unifying themes.

9. Promote best practice training on interaction with the media, outreach to citizens and school children on hazard preparedness, and interaction between volcanologists and Volcanic Ash Advisory Centres in the region.

10. Convene a G-EVER workshop every 2 years in Asia-Pacific countries in conjunction with major regional events (such as AOGS, WPGM and AGU meetings).

The G-EVER Promotion Team of Geological Survey of Japan was formed in November 2012. The G-EVER Hub website (Fig. 2; http://g-ever.org) was setup to promote the exchange of information and knowledge about volcanic and seismic hazards among the AsiaPacific countries. Establishing or endorsing standards on data sharing and analytical methods is important to promote the sharing of data and analyses results. The major activities of G-EVER include participation in global risk reduction efforts such as the Integrated Research on Disaster Risk (IRDR) Program, Global Earthquake Model (GEM) and Global Volcanic Model (GVM).

The 1st G-EVER International Symposium was held in Tsukuba, Japan on March 11, 2013 which coincided with the second anniversary of Tohoku Earthquake (Takarada, 2013b). The 2nd G-EVER Symposium and IUGS\&SCJ International Workshop was held in Sendai, Tohoku Japan on October 19-20, 2013. The workshop was attended by 94 individuals from 12 nations and regions and 30 national and international institutes. The participants crafted the Sendai Agreement and unanimously endorsed it (See Tsukuda and G-EVER Promotion team (2014), this volume).

Several G-EVER Working Groups and projects were proposed such as: (1) Risk mitigation of large-scale earthquakes WG, (2) Risk mitigation of large-scale volcanic eruptions WG, (3) Next-generation volcanic hazard assessment WG, and (4) Asia-Pacific region earthquake and volcanic hazard mapping project.

\section{G-EVER volcanic hazard assessment support system}

The next-generation volcano hazard assessment WG is developing a useful system for volcanic eruption prediction, risk assessment, and evacuation strategy at various eruption stages. The G-EVER Volcanic Hazard Assessment Support System is based on volcanic eruption history datasets, volcanic eruption database and numerical simulations (Fig. 3, Takarada, 2013c). Volcanic eruption histories including precursor phenomena leading to major eruptions are important to predict future volcanic eruptions. Likewise, a high quality volcanic

\section{G-EVER Volcanic Hazard Assessment Support System}

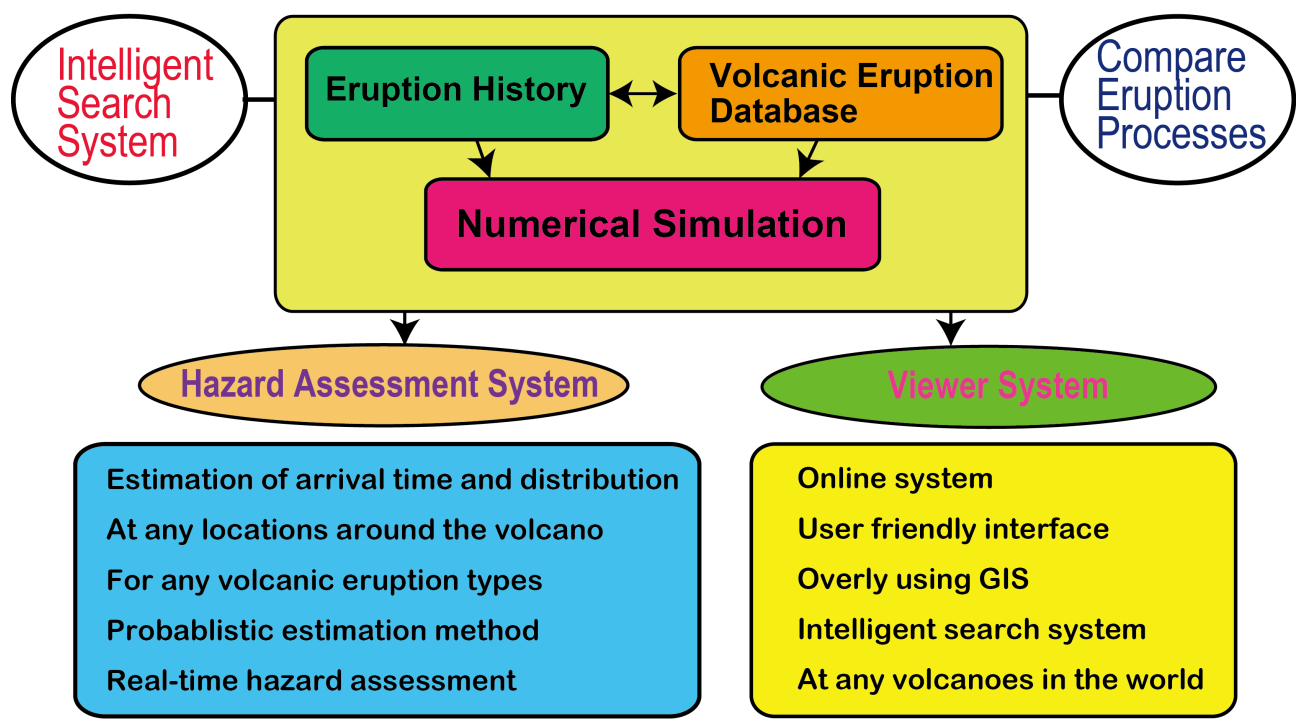

Figure 3. Concept diagram of the G-EVER volcanic hazard assessment support system. The system is based on eruption history, volcanic eruption database and numerical simulation. 


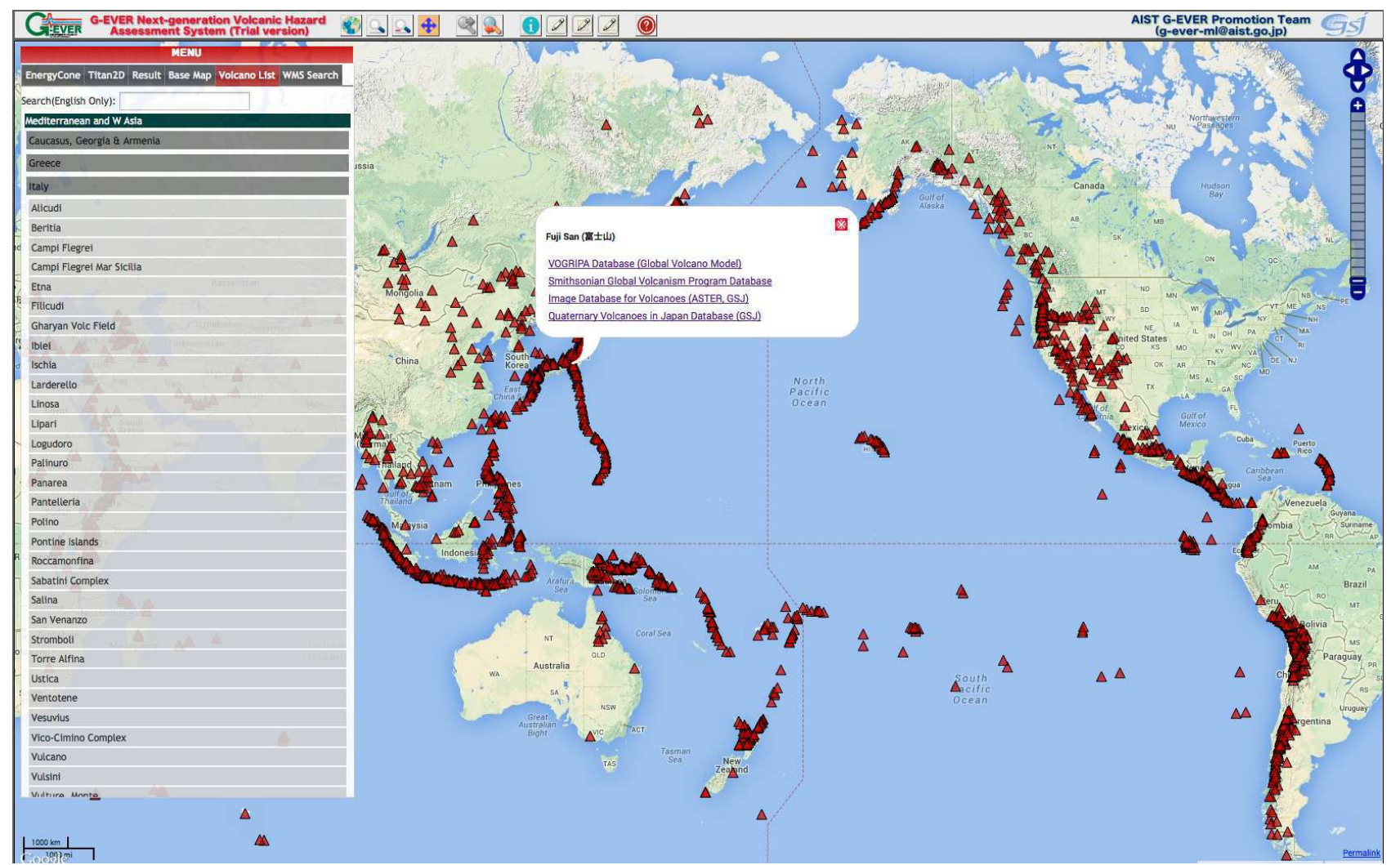

Figure 4. G-EVER volcanic hazard assessment support system (Trial version). Any volcano can be searched from the Quaternary volcano list in the world. Links to major volcano databases such as Smithsonian Global Volcanism Database, VOGRIPA Database (Global Volcano Model), ASTER satellite image database (GSJ) and Quaternary Volcanoes in Japan (GSJ).

http://volcano.g-ever1.org/vhazard/HazardAssessment/

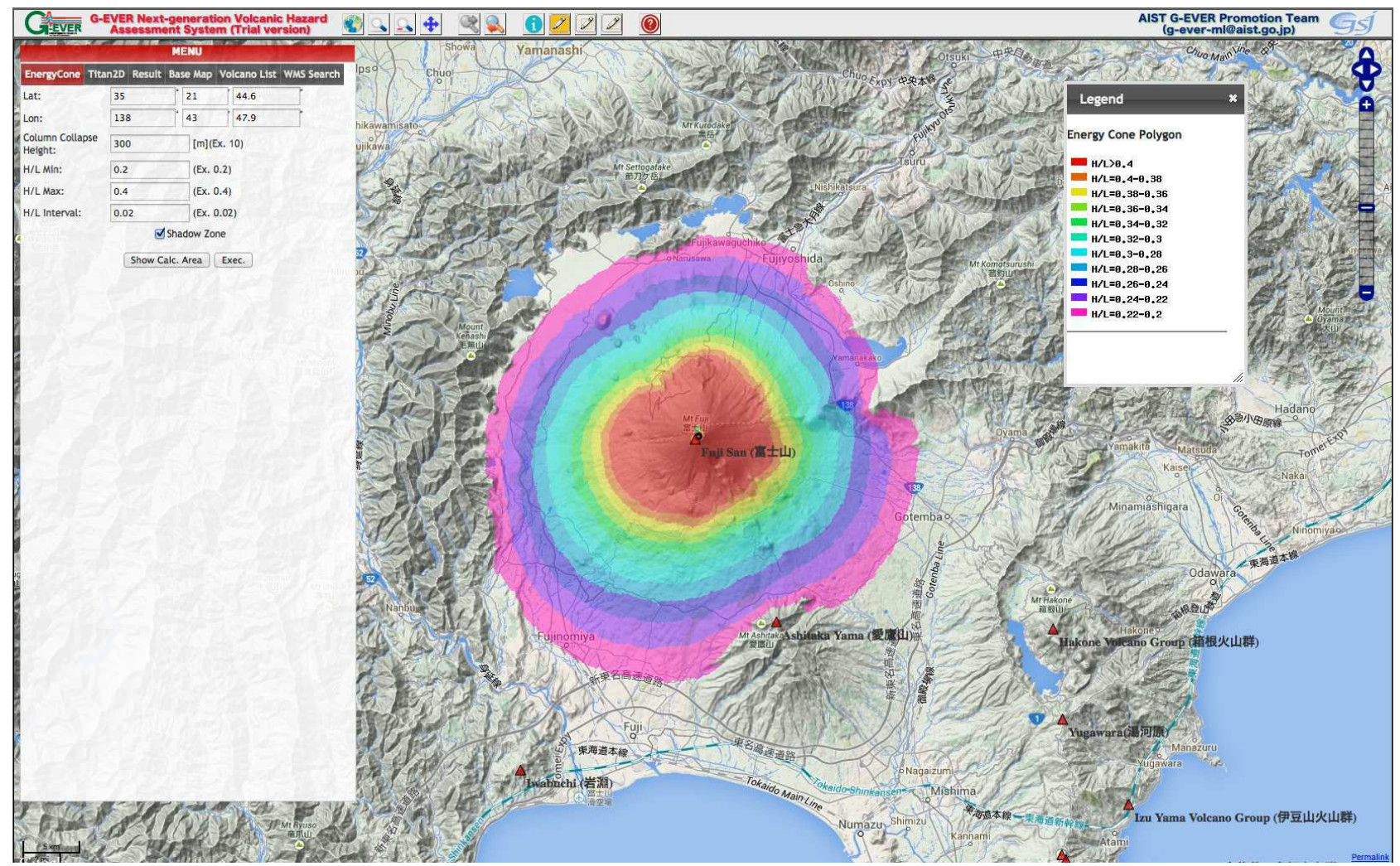

Figure 5. An energy-cone simulation result at Fuji Volcano, Japan, using G-EVER volcanic hazard assessment support system. Almost all volcanoes in the world can be evaluated with this system because of the wide coverage of ASTER Global DEM. 
eruption database, which contains compilations of eruption dates, volumes, and styles, is important for the volcano hazard assessment system. Formulating international standards on how to estimate the volume of volcanic materials is necessary to make a high quality volcanic eruption database. GIS based spatial distribution database of volcanic materials (e.g. Tephra and pyroclastic flow distributions) is required for accurate area and volume estimation and risk assessments.

The volcanic eruption database is developed based on past eruption results, which only represent a subset of possible future scenarios. Therefore, numerical simulations with controlled parameters are needed for more precise volcanic eruption predictions. The "best-fit" parameters of the past worldwide major eruptions have to be estimated and the simulation results database should be made.

The use of the system should enable the visualization of past volcanic eruptions datasets such as distributions, eruption volumes and eruption rates, on maps and diagrams using timeline and GIS software. Similar volcanic eruption types should be easily searchable

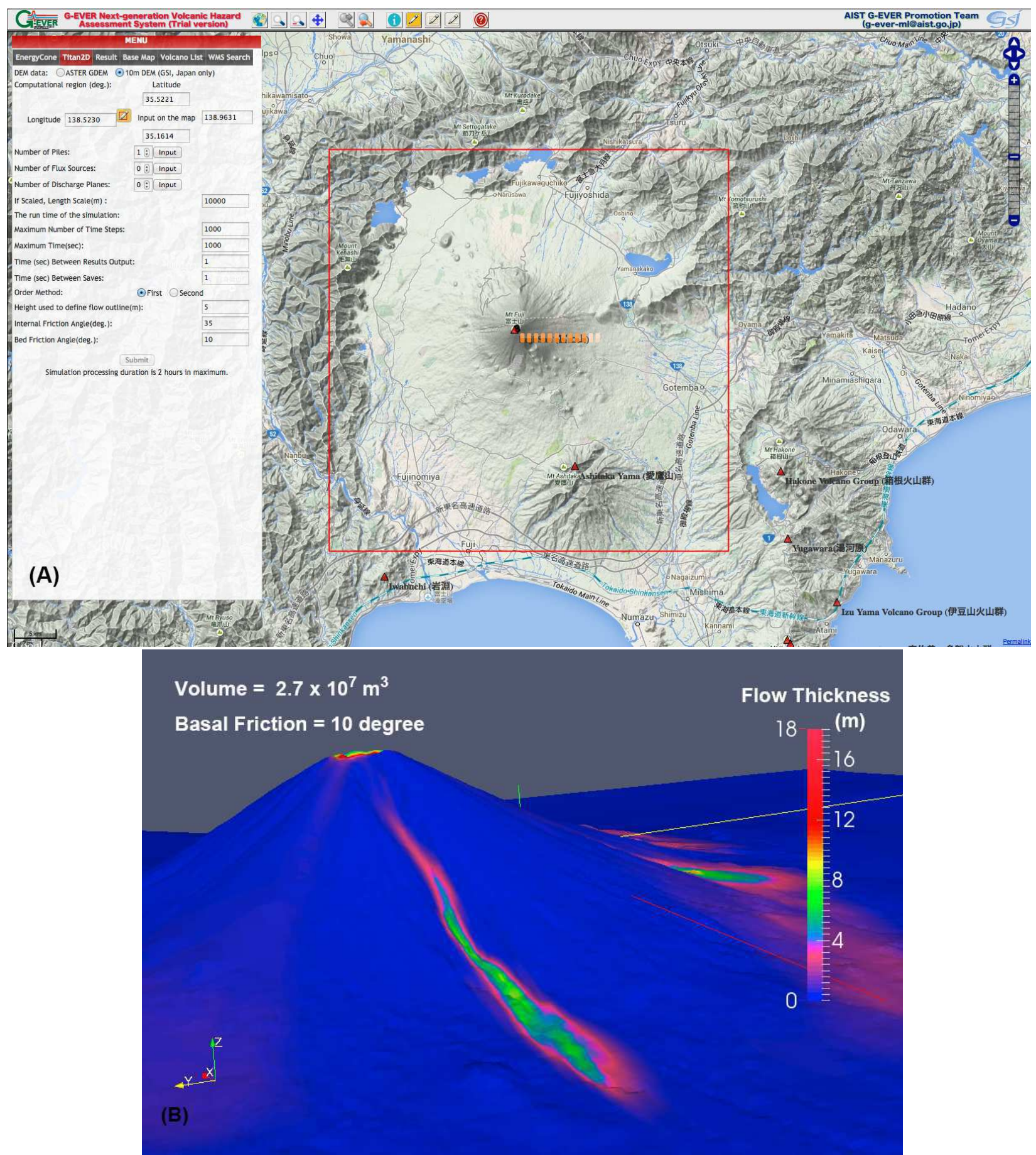

Figure 6. A Titan2D simulation result at Fuji Volcano, Japan, using G-EVER volcanic hazard assessment support system. (A) Online simulation view on the Titan2D menu. (B) the result can be visualized using a free 3D software (eg. Paraview). A pyroclastic density current, derived from a summit eruption with $2.7 \times 10^{7} \mathrm{~m}^{3}$ in volume, descending down along a western valley. A 10-degree basal friction was used for the simulation. 


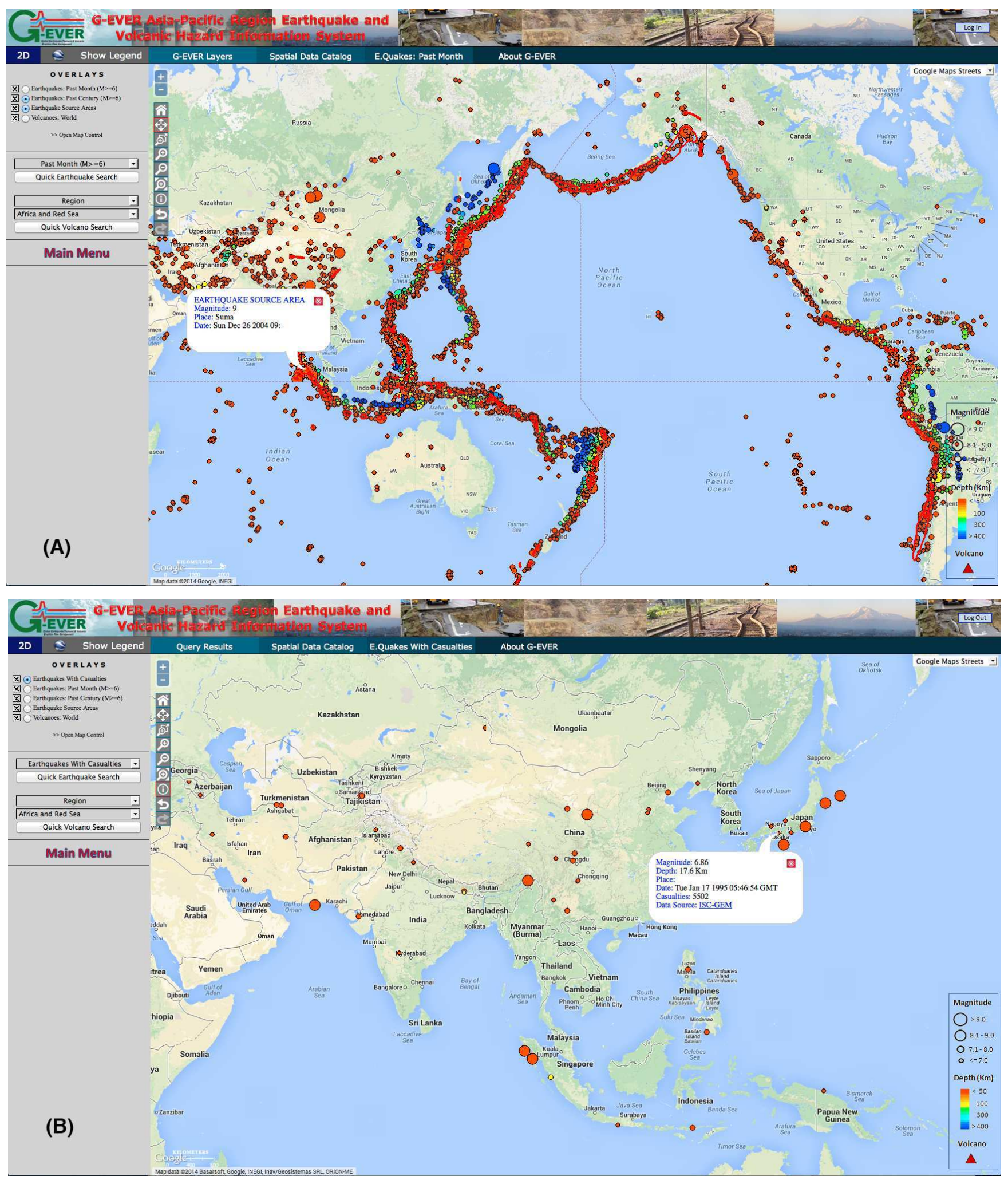

Figure 7. Preliminary version of G-EVER Asia-Pacific Region Earthquake and Volcanic Hazard Information System (http://ccop-geoinfo.org/ G-EVER). (A) Distribution of epicenter of large-scale earthquakes (M>6) since 1971 (USGS and ISC-GEM) are shown. Red-line areas indicate large-scale earthquake source regions. Detailed information is available by clicking on earthquake epicenters. (B) Epicenter of large-scale earthquakes with more than 1,000 casualties. 


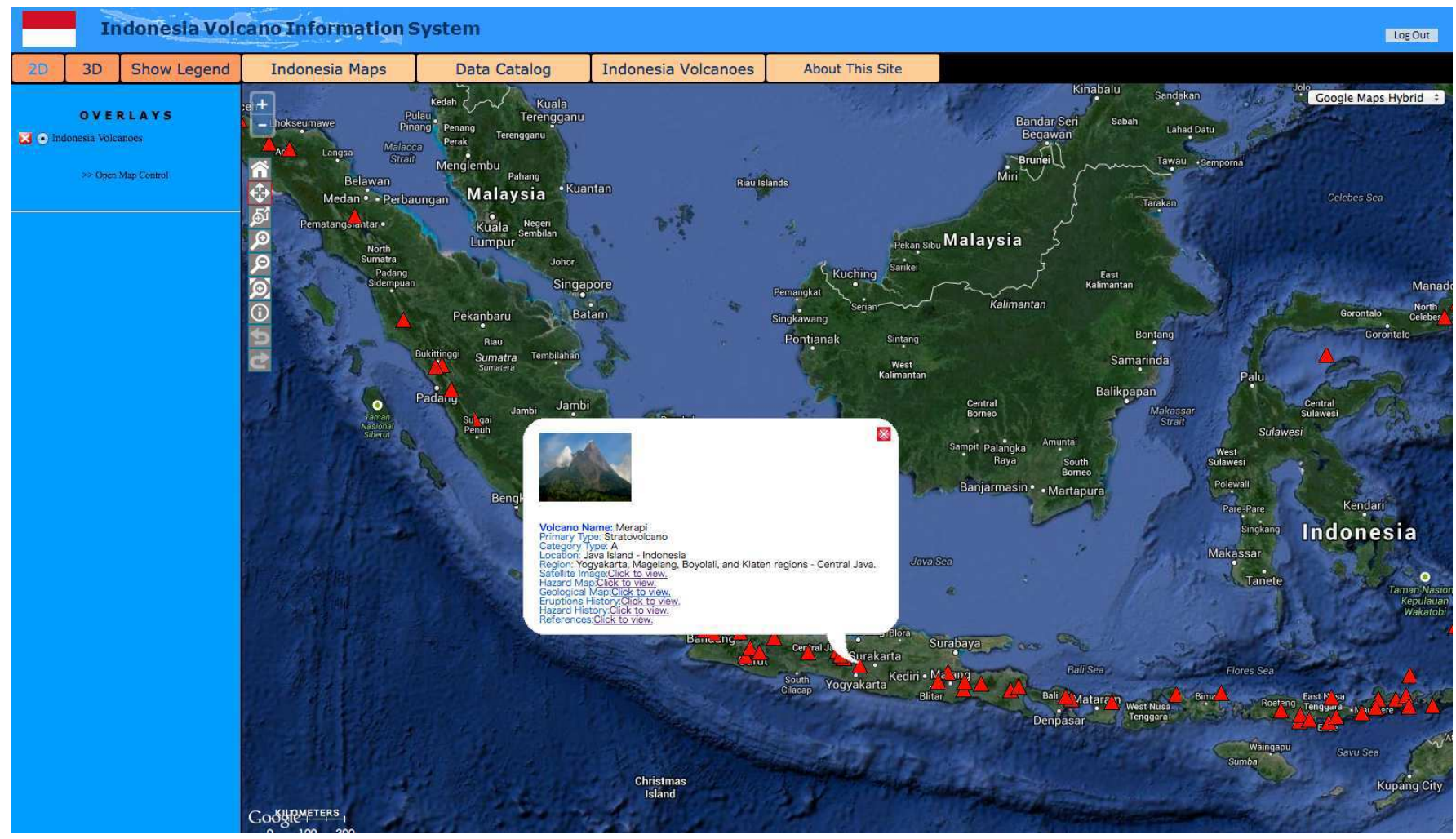

Figure 8. Preliminary version of Indonesia Volcano Information System. Type A volcanoes, which erupted after 1600AD, are shown on the map. Volcano type, category, satellite image, hazard map, geological map, eruption history, hazard history and references of each volcano can be seen on this system.

from the eruption database. Using the volcano hazard assessment system, the time and area that would be affected by volcanic eruptions at any locations near the volcano can be predicted using numerical simulations. The system should estimate volcanic hazard risks by overlaying the distributions of volcanic deposits on major roads, houses and evacuation areas using GIS enabled systems. The G-EVER hazard assessment support system is implemented with a user-friendly interface, making the risk assessment system readily usable and accessible online.

A preliminary version of the G-EVER volcanic hazard assessment support system (Fig. 4) that can run energy cone (Fig. 5; Marlin and Sheridan, 1982) and Titan2D (Fig. 6; Pitman et al., 2003; Sheridan et al., 2004) simulations at any volcano in the world is available since 2013. The system using ASTER Global DEM (30m resolution) and $10 \mathrm{~m}$ DEM dataset is used in Japan region. Links to major volcanic databases, such as Smithsonian GVP (Global Volcanism Program, http://www.volcano.si.edu/), VOGRIPA (Volcano Global Risk Identification \& Analysis Project; http://www.bgs.ac.uk/vogripa/), ASTER Satellite image (https://gbank.gsj.jp/vsidb/image/), and Volcanoes of Japan (https://gbank.gsj.jp/volcano/), are available from each volcano on the map. Almost all volcanoes in the world can be evaluated using this volcanic hazard assessment support system. Currently, the system covers more than 3200 Quaternary volcanoes worldwide. Links to major volcanic databases in the world are useful to examine eruption history in detail. Using Google and Bing maps as base maps provides more information for hazard evaluations. Combining simulation results and distributions of roads, hospitals, evacuation sites and airports are useful for hazard and risk assessments.

\section{Asia-Pacific region earthquake and volcanic hazard mapping project}

The Asia-Pacific region earthquake and volcanic hazard mapping project aims to develop an advanced online information system that provides past and recent earthquake and volcanic eruption information (e.g. age, location, scale, affected areas and fatalities) and risk assessment tools for earthquake and volcanic eruption hazards. A printed map version will also be published as the new version of the Eastern Asia Geological Hazard Map (Kato and Eastern Asia Natural Hazards Mapping Project, 2002) of the Commission for the Geological Map of the World (CGMW). The online hazard information system provides useful information about earthquake and volcanic hazards in an interactive and user-friendly interface (Fig. 7). Past and recent large-scale earthquakes and volcanic eruptions, tsunami inundation areas, active faults distributions, and major landslides are going to be shown on the map. Links to major earthquakes and volcanic eruptions databases are available in the system. The earthquake and volcanic eruption hazard mapping project will be implemented with the cooperation of major research institutes and organizations in the Asia-Pacific region such as PHIVOLCS (Philippine), CVGHM (Indonesia), GNS Science (New Zealand), EOS (Singapore), USGS (USA) and CCOP (Coordinating Committee for Geoscience Programmes in East and Southeast Asia). A preliminary hazard information website collaborating with CVGHM is under construction (Fig. 8). Volcano type, category, satellite image, hazard map, geological map, eruption history, hazard history and reference of active volcanoes can be displayed on this system. 


\section{Conclusion}

The G-EVER consortium among the Asia-Pacific geohazard research institutes was started in 2012 to reduce the risks caused by earthquakes, tsunamis and volcanic eruptions worldwide. The G-EVER1 accord with 10 recommendations was approved by G-EVER1 workshop participants. The next-generation volcanic hazard assessment Working Group released the G-EVER hazard assessment support system making the hazard and risk assessment easily usable and accessible online. The Asia-Pacific region earthquake and volcanic hazard mapping project made a preliminary hazard mapping system that provides earthquake and volcanic hazard information, risk assessment tools and links to major databases in the world. The project plans to create the system with the cooperation of Asia-Pacific countries.

\section{Acknowledgements}

We greatly appreciate the discussion and generous supports from the president, Dr. Eikichi Tsukuda (AIST), vice president, Dr. John Eichelberger (Univ. of Alaska) and the Management Board and Steering Committee Members of G-EVER Consortium.

\section{References}

Kato, H. and Eastern Asia Natural Hazards Mapping Project, 2002, Eastern Asia Geological Hazards Map, 1:7,700,000. Geological Survey of Japan, AIST, 2 sheet maps and explanatory note, $49 \mathrm{p}$.

Marlin, M.C. and Sheridan, M.F., 1982, Computer-assisted mapping of pyroclastic surges. Science, v. 13, pp. 637-640.

Pitman, E.B., Patra, A., Bauer, A., Sheridan, M., Bursik, M., 2003, Computing debris flows and landslides. Phys. Fluids, v. 15, pp. 3638-3646.

Sheridan, M.F., Stinton, A.J., Patra, A., Pitman, E.B., Bauer, A. and Nichita, C.C. (2004) Evaluating Titan2D mass-flow model using the 1963 Little Tahoma Peak avalanches, Mount Rainier, Washington, Jour. Volcanol. Geotherm. Res., v. 139, pp. 89-102.

Takarada, S., 2013a, Asia-Pacific Region Global Earthquake and Volcanic Eruption Risk Management (G-EVER) Consortium: the new hazard mitigation activities, IAVCEI 2013 abstract, Kagoshima, 4A1_4HO4.

Takarada, S., 2013b, G-EVER Consortium activities and the next-generation volcanic hazard assessment system. Proceeding of the 1st Asia-Pacific Region Global Earthquake and Volcanic Eruption Risk Management (GEVER) International Symposium. Open-file report of Geological Survey of Japan, no. 583, pp. 12-22.

Takarada, S., 2013c, The next-generation real-time volcanic hazard assessment system in G-EVER, IAVCEI 2013 abstract, Kagoshima, 4P1_4D-O21.

*G-EVER Promotion Team Members: Shinji Takarada, Yasuto Kuwahara, Yuzo Ishikawa, Naoji Koizumi, Toshihiro Uchida, Akira Takada, Norio Shigematsu, Ryuta Furukawa, Tadashi Maruyama, Ryosuke Ando, Junko Hara and Joel Bandibas in Geological Survey of Japan, AIST. 